DOI: $10.12731 / w s d-2017-1-29-40$

УДК 616.5-001.1-616-059

\title{
ИССЛЕДОВАНИЕ КАЧЕСТВА ЖИЗНИ ПАЦИЕНТОВ В РЕАБИЛИТАЦИОННОМ ПЕРИОДЕ ПОСЛЕ ХИМИЧЕСКОГО ПИЛИНГА
}

\author{
Кузнецова Е.С.
}

В статье представлень данные о влиянии применения жидкостей с различным окислительно-восстановительным потенциалом в период реабилитации после косметологических процедур на качество жизни пациентов. Цель исследования: установить влияние жидкостей с различным окислительно-восстановительным потенциалом качество жизни пациентов в постпилинговом периоде. Пациентам была проведена процедура ретиноевого химического пилинга. При применении жидкостей с различным окислительно-восстановительным потенциалом осложнения в реабилитационном периоде после этой процедуры были значительно менее выраженными. Полученные данные характеризуют течение реабилитационного периода после химического пилинга при применении жидкостей с различным окислительно-восстановительным потенциалом как более благоприятное, с более высоким качеством жизни.

Ключевые слова: жидкости с различным окислительно-восстановительным потенциалом; ретиноевый пилинг; постпилинговый период; осложнения косметологических процедур; Дерматологический Индекс Качества Жизни (ДИКЖ).

\section{THE STUDY OF QUALITY OF LIFE FOR PATIENTS IN REHABILITATION PERIOD AFTER A CHEMICAL PEEL}

Kuznetsova E.S.

The article presents data about the effect of liquids with different redox potential in the period of recovery after cosmetic procedures on the quality of life of patients. Patients underwent the procedure retinoic peel. Objective is 
determine the influence of liquids with different redox potential quality of life of patients after the peeling. Complications were significantly less pronounced in the rehabilitation period after the procedure in the application of liquids with different redox potential. The data obtained characterize the course of rehabilitation period after a retinoic peel when using liquids with different redox potential as more favorable with a higher quality of life.

Keywords: liquids with different redox potential; retinoic peeling; post-peeling period; complications of cosmetic procedures; the Dermatology Life Quality Index (DLQI).

\section{Введение}

В связи с развитием индустрии красоты, появлением на рынке новых препаратов и методов косметологических вмешательств возросло число осложнений этих процедур. По мере накопления клинического опыта проведения поверхностных и срединных пилингов стали чаще выявляться осложнения и побочные эффекты, увеличилось число жалоб пациентов на сложности ухода за кожей в период реабилитации, появление осложнений несмотря на тщательное соблюдение всех назначений и рекомендаций. Явления крупнопластинчатого шелушения, кожный зуд, не проходящая в течение нескольких недель гиперпигментация в области воздействия, обострения лабиального герпеса, появление гнойничковых высыпаний, необходимость применения смягчающих кожу кремов и солнцезащитных средств по нескольку раз в день на протяжении всего реабилитационного периода (до трех недель) существенно снижают качество жизни пациентов, влияют на их трудовую деятельность, социальную активность и возможности занятий спортом.

Химический пилинг представляет собой контролируемое химическое повреждение верхних слоев эпидермиса и дермы, по сути, дозированный химический ожог. В результате этого воздействия помимо воспалительной реакции, начинается процесс заживления, стимулируется регенерация тканей $[1,2,3,4,5,6,7]$.

Уход за кожей в реабилитационном периоде после проведения травматичных косметологических воздействий направлен на восстановление барьерных свойств эпидермиса, профилактику образования рубцов, уменьшение выраженности эритемы $[4,8,9,10]$. Несмотря на наличие значительного количества медикаментозных средств для дезинфекции и ухода за поврежденной кожей, проблема поиска наиболее эффективных и безопасных из них остается актуальной. В связи с этим наше внимание 
привлекли жидкости с различным окислительно-восстановительным потенциалом [3].

Жидкость (А), имеющая положительный окислительно-восстановительный потенциал (ОВП), и жидкость (К), имеющая отрицательный ОВП. Жидкость (А), имеющая положительный окислительно-восстановительный потенциал ОВП - плюс 650-720 мВ является экологически чистым безопасными для человека и животных стерилизирующим и дезинфицирующим раствором, который уничтожают бактерии, вирусы и патогенные грибки. Его безопасность для человека и животных определяется тем, что он представляют собой неорганические короткоживущие пероксидные соединения. Он обладает антимикробными свойствами. Жидкость (А) не оказывает на кожу местно-раздражающего действия $[11,12]$. В литературе представлены данные о лечении жидкостью, имеющей положительный окислительно-восстановительный потенциал (А) с последующим применением жидкости (К) с отрицательным окислительно-восстановительным потенциалом больных с гнойными хирургическими заболеваниями $[11,13]$. Жидкость $($ К) с отрицательным ОВП минус 450-550 мВ - обладает антиоксидатным и антимутагенным действием, снижает аллергические реакции, обладает антисептическим действием, стимулирует процессы роста и регенерации [3, 14, 15, 19]. Представленные свойства этих безопасных жидкостей с различным окислительно-восстановительным потенциалом, явились обоснованием их применения для профилактики и снижения выраженности осложнений косметологических процедур [19, 20].

\section{Цель работы}

Установить влияние жидкостей с различным окислительно-восстановительным потенциалом на качество жизни пациентов в постпилинговом периоде.

\section{Материалы и методы исследования}

В исследовании приняли участие 26 пациентов, которым была проведена процедура ретиноевого химического пилинга Block Age Peel Gel MedicControlPeel на основе третиноина. Препарат Block Age Peel Gel coдержит 5\% ретиноевой кислоты (третиноин), 15\% азелаиновой кислоты и $50 \%$ диметилсульфоксида. При проведении исследования были соблюдены этические нормы, изложенные в Хельсинской декларации 1964 года, модифицированной 41 Всемирной Ассамблеей, Гонконг, 1989 г. И 52-й 
генеральной Ассамблеей ВМА, Эдинбург, Шотландия (Великобритания), октябрь 2000 г., в Лиссабонской Декларации о правах пациентов, принятой 34-й Всемирной Медицинской ассамблеей, Лиссабон (Португалия), сентябрь/октябрь 1981 г., в разделе V Кодекса врачебной этики, одобренного II (XVIII) Всероссийским Пироговским съездом врачей (07.06.1997г.).

Пациенты были распределены в равном количестве на 2 группы. Пациенты 1-й группы получали стандартное лечение в соответствии с протоколом процедуры, пациенты 2-й группы помимо стандартного лечения, проводилось местное применение жидкостей с различным окислительно-восстановительным потенциалом. Критерии включения: угревая болезнь легкой и средней степени тяжести, себорея, рубцы постакне, возрастные изменения кожи, нарушения микрорельефа кожи, гиперпигментация, хлоазмы, гиперкератоз, в том числе фолликулярный гиперкератоз, кератомы $[1,15,16]$. Критерии исключения: индивидуальная непереносимость ингредиентов пилингового состава, нарушение целостности кожных покровов, активный воспалительный процесс на коже, обострение герпеса, тяжелые соматические заболевания, инфекционные заболевания и лихорадочные состояния, беременность, лактация, сахарный диабет, прием ретиноидов, печеночная недостаточность и другие тяжелые соматические заболевания $[2,3,10,15,20]$. В постпилинговом периоде пациенты обеих групп использовали крем Vegefarma по мере возникновения ощущений стянутости и сухости кожи [10]. Помимо этого, утром применяли любой солнцезащитный крем с фактором защиты не ниже SPF 50 (на выбор пациента) в течение всего постпилингового периода [10]. Пациенты второй группы помимо этого применяли салфетки нетканого полотна спанлейс, смоченные жидкостью А (pH - 6,2-68, ОВП - плюс 650-720 мВ), а затем жидкостью К 1 раз в сутки, которые находились на коже лица до высыхания. Пациенты оценили состояние своей кожи сразу после проведения процедуры и на 7 , 14, 21 дни по четырехбальной шкале (от 0 до 4 баллов). Была проведена оценка следующих симптомов: боли, покраснения кожи, кожного зуда, шелушения, пигментации кожи или депигментации кожи в области воздействия, воспалительной инфильтрации, наличия пузырей, эрозий гнойничков. Помимо этого, все пациенты заполнили бланки опросника ДИКЖ [16]. Дерматологический Индекс Качества Жизни (ДИКЖ или The Dermatology Life Quality Index (DLQI)) применяется дерматологами для оценки степени негативного воздействия дерматологического заболевания на разные аспекты жизни пациента, характеризующие качество 
его жизни в целом. Индекс был разработан специалистами Уэльского университета (авторские права принадлежат AY Finlay, Gk Khan, April 1992). Индекс ДИКЖ используется как критерий оценки эффективности лечения дерматологического заболевания [16]. Полученный цифровой показатель отражает уровень негативного воздействия заболевания на качество жизни пациента.

В проводимом исследовании не ставилась цель изучить исходный статус пациентов, влияние на их качество жизни того дерматологического состояния, которое привело их на процедуру ретиноевого пилинга. Хронические заболевания в стадии обострения, нарушения целостности кожных покровов в области воздействия, сахарный диабет, как возможная причина кожного зуда, служили критериями исключения пациентов. Анкетирование пациентов перед процедурой по опроснику или непосредственно сразу после воздействия не производилось, так как не успевали развиться все осложнения, характерные для периода реабилитации после ретиноевого пилинга. Оценивалась динамика развития осложнений и эффективность их коррекции. Поэтому пациенты заполняли опросник ДИКЖ на 7 сутки, 14 сутки, когда выраженность осложнений была максимальной, и на 21 сутки исследования, к окончанию реабилитационного периода после произведенного косметологического вмешательства. Полученные результаты обработаны статистически с использованием пакета программ Statistica 10.0 с вычислением среднего арифметического, стандартной ошибки, t-критерия Стьюдента, были применены непараметрические критерии (сравнение между группами), проведен корреляционный анализ по Пирсону между тяжестью кожных проявлений и изменениями психофизиологического состояния [17].

\section{Результаты исследования и их обсуждение}

Основные данные представлены в таблице 1. У пациентов второй группы выраженность покраснения кожи после процедуры на седьмой день на 22\% меньше, выраженность кожного зуда на 24,53\% меньше, шелушения - на 79\% ниже, чем у пациентов, получавших стандартное лечение. Выраженность гнойничков у второй группы пациентов стала меньше на $6,70 \%$ по сравнению с показателями пациентов первой группы. Ни у одного пациента второй группы не было проявлений лабиального герпеса в виде пузырей. Высыпания герпеса на губах в раннем постпилинговом периоде следует считать осложнением процедуры. Приведенные данные являются статистически достоверными. По показателям боли во время 
процедуры, выраженности пигментации, эрозий на коже между группами пациентов статистически достоверных различий не выявлено. На 14 день после процедуры выраженность кожного зуда у пациентов второй группы уменьшилась в 4 раза, выраженность шелушения - в 4,86 раз по сравнению со стандартным лечением. Количество гнойничковых высыпаний снизилось в 3,25 раз по сравнению с пациентами первой группы.

Таблица 1.

Оценка состояния кожных покровов лица самими пациентами

\begin{tabular}{|c|c|c|c|c|c|c|c|c|}
\hline Признаки & 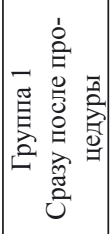 & 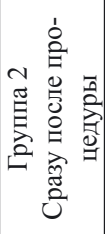 & 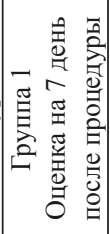 & 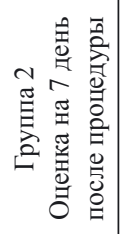 & 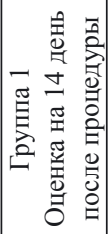 & 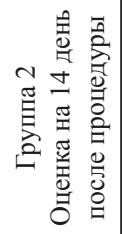 & 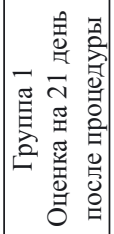 & 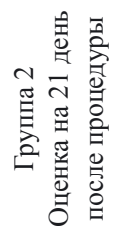 \\
\hline Боль & $3,15 \pm 0,21$ & $3,15 \pm 0,21$ & 0 & 0 & 0 & 0 & 0 & 0 \\
\hline $\begin{array}{l}\text { Покраснение } \\
\text { кожи }\end{array}$ & $2,41 \pm 0,46$ & $2,35 \pm 0,70$ & $1,00 \pm 0,58$ & $0,22 \pm 0,16^{*}$ & 0 & 0 & 0 & 0 \\
\hline Кожный зуд & $2,40 \pm 0,18$ & $2,40 \pm 0,17$ & $2,16 \pm 0,50$ & $0,53 \pm 0,44 *$ & $0,65 \pm 0,16$ & $0,15 \pm 0,12 *$ & 0 & 0 \\
\hline Шелушение & 0 & 0 & $4,00 \pm 0,00$ & $3,16 \pm 0,08 *$ & $0,65 \pm 0,14$ & $0,08 \pm 0,08^{*}$ & 0 & 0 \\
\hline Пигментация & $0,83 \pm 0,58$ & $1,02 \pm 0,76$ & $1,08 \pm 0,78$ & $0,67 \pm 0,7$ & $1,00 \pm 0,38$ & $1,00 \pm 0,27$ & $0,68 \pm 0,16$ & $0,17 \pm 0,12 *$ \\
\hline $\begin{array}{l}\text { Воспалительная } \\
\text { инфильтрация }\end{array}$ & $1,38 \pm 0,67$ & $1,35 \pm 0,58$ & $0,68 \pm 0,51$ & $0,68 \pm 0,51$ & $0,16 \pm 0,07$ & $0,16 \pm 0,12$ & $0,16 \pm 0,14$ & $0,08 \pm 0,08$ \\
\hline Пузыри & 0 & 0 & $0,18 \pm 0,08$ & $0^{*}$ & 0 & 0 & 0 & 0 \\
\hline Эрозии & 0 & 0 & $0,38 \pm 0,19$ & $0,32 \pm 0,14$ & 0 & 0 & 0 & 0 \\
\hline Гнойнички & $1,40 \pm 0,58$ & $1,41 \pm 0,68$ & $1,18 \pm 0,68$ & $0,08 \pm 0,16^{*}$ & $0,52 \pm 0,17$ & $0,16 \pm 0,12 *$ & $0,32 \pm 0,25$ & $0,08 \pm 0,08$ \\
\hline
\end{tabular}

$* \mathrm{p}<0,05$

К 21 дню все пациенты отмечали лишь некоторые из нежелательных явлений, такие как пигментация кожи в области воздействия, воспалительная инфильтрация, гнойнички. У пациентов на фоне применения жидкостей с различным окислительно-восстановительным потенциалом пигментация кожи в области воздействия стала менее выраженной в 4 раза по сравнению с пациентами, получавшими стандартное лечение. Значимых различий по другим признакам на 21 день после процедуры между двумя группами пациентов не наблюдалось.

Цифровой показатель в баллах по опроснику ДИКЖ переведен в проценты. За 100\% приняты 30 баллов - максимально возможный показа- 
тель. На рисунке 1 представлены данные об изменении ДИКЖ в течение постпилингового периода.

На седьмые сутки после процедуры значение ДИКЖ характеризовало постпилинговый период как оказывающий чрезвычайно сильное влияние на жизнь пациентов в обеих группах. Однако при применении жидкостей с различным окислительно-восстановительным потенциалом этот показатель был ниже на 20,93\%. К 14-м суткам у пациентов первой группы состояние кожи оказывало очень сильное влияние на жизнь, у пациентов второй группы умеренно сильное влияние. Разница между средними баллами у этих двух групп пациентов составила 8,15\%. К 21 суткам реабилитационного периода состояние кожи оказывало незначительное влияние на жизнь пациентов первой группы, и не оказывало влияния на качество жизни пациентов второй группы. Разница индексов составила 9,37\%.

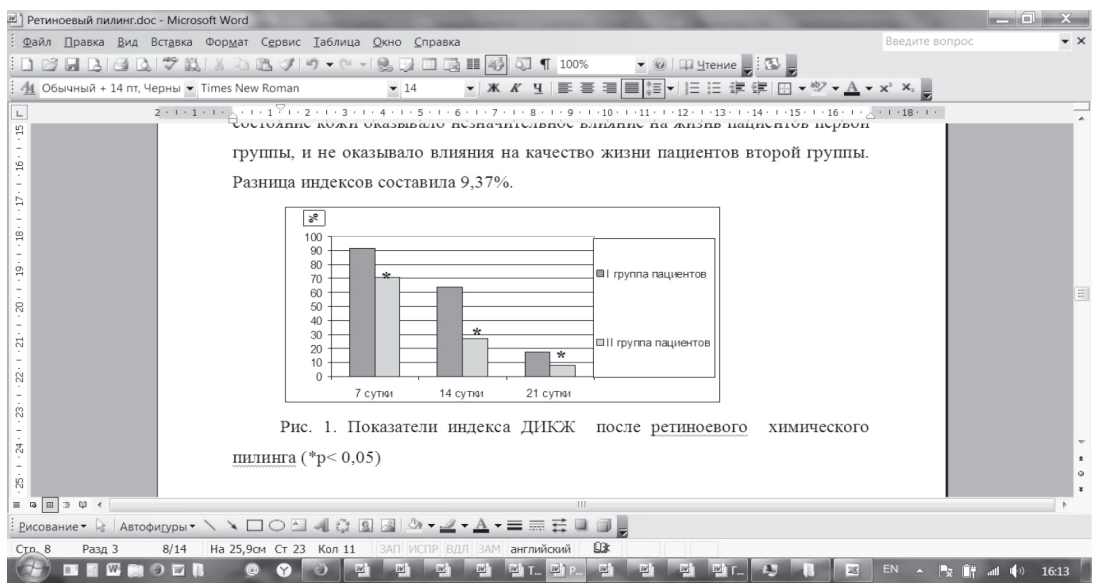

Рис. 1. Показатели индекса ДИКЖ после ретиноевого химического пилинга $(* \mathrm{p}<0,05)$

\section{Заключение}

Покраснение кожи, кожный зуд, шелушение, доставляют наибольший дискомфорт пациентам к седьмым суткам постпилингового периода. Эти симптомы были настолько сильно выражены после процедуры ретиноевого пилинга, что снижали качество жизни пациентов. К 14-м суткам после процедуры пациентов наиболее беспокоили сохраняющиеся шелушение, кожный зуд и присоединение небольшого количества гнойничков. При дополнении стандартного лечения применением жидкостей с раз- 
личным окислительно-восстановительным потенциалом в постпилинговом периоде повышалось качество жизни пациентов вследствие меньшей выраженности указанных симптомов. К 21-м суткам постпилингового периода процедура ретиноевого пилинга оказывала незначительное влияние или не влияла вовсе на качество жизни пациентов обеих групп.

Включение в программу лечения косметологических осложнений жидкостей с различным окислительно-восстановительным потенциалом оказало позитивное действие на исход процедуры. Можно рекомендовать дополнение стандартной терапии осложнений косметологических процедур применением жидкостей с различным окислительно-восстановительным потенциалом: жидкости (А) с параметрами рН - 6,2-6,8; ОВП - плюс 650-720 мВ местно и жидкости (К) с параметрами рН 7,8-9,0; ОВП - минус 450-550 мВ местно 2 раза в сутки в течение 3-х недель постпилингового периода.

Автор не имеет явных и потенциальных конфликтов интересов, связанных с проведением исследования и публикацией этой статьи.

\section{Список литературы}

1. Альбанова В.И. Ретиноиды - «золото» косметологии / В.И. Альбанова // Эстетическая медицина. 2009. Т8. №4. С. 385-394.

2. Кубанова А.А. Химический пилинг в косметологии / А.А. Кубанова, и др. // Экспериментальная и клиническая дерматокосметология. 2004. №1. C. 24-28.

3. Кузнецова Е.С., Резников К.М. Оптимизация постпилинговых процессов в косметологии / Е.С. Кузнецова, К.М. Резников // Труды XXI международной конференции и дискуссионного научного клуба «Новые информационные технологии в медицине, биологии, фармакологии и экологии». Украина, Крым, Ялта-Гурзуф, 2013. С. 133-134.

4. Скорогудаева И.Н. Химические пилинги сегодня: новые возможности в борьбе со старением / И.Н. Скорогудаева // Kosmetik international. 2005. № 4. C. 72-75.

5. Эрнандес Е.И. Липидный барьер кожи и косметические средства. Изд. 3-е, дополненное / Е.И. Эрнандес, А.А. Марголина, А.О. Петрухина. М.: ООО «Фирма КЛАВЕЛЬ», 2005. С. 252.

6. Эрнандес Е.И., Пономарев И.В., Ключарева С.В. Современные пилинги: химический пилинг, лазерная шлифовка, механическая дермабразия, плазменная шлифовка / Е.И. Эрнандес, И.В. Пономарев, С.В. Ключарева М.: «Косметика \& Медицина», 2011. 160 с. 
7. Резников К.М. Безопасность применения элекроактивированных растворов натрия хлорида с лечебной целью: монография / К.М. Резников, А.Д. Брезднюк, Ю.Н. Латышева. Воронеж: ВГМА, 2010. 144 с.

8. Pyruvic acid peels for the treatment of photoaging / I. Ghersetich et al. // Dermatol Surg. 2004. Vol. 30(1), pp. 32-36.

9. Obagi Z.E. TCA-based blue peel: a standardized procedure with depth control / Z.E. Obagi, S.Obagi, S. Alaiti et al. // Dermatol . Surg. 1999. Vol. 25, №10, pp. 773-780.

10. Moy L.S., Howe K., Moy R.L. Glycolic acid modulation of collagen production in human skin fibroblast cultures in vitro.// Dermatol. Surg, 1996; 22(5), pp. 439-441.

11. Девятов В.А. Использование нейтрального анолита АНК при предупреждении гнойных осложнений воспалительных заболеваний / В.А. Девятов, С.В. Петров, Г.А. Белобородов // Докл. и краткие сообщ. Третий междунар. симп. «Электрохимическая активация в медицине, сельском хозяйстве, промышленности». М., 2001. С. 133-135.

12. Бахир В.М. Некоторые аспекты получения и применения электрохимически активированного раствора - анолита АНК / В.М. Бахир, В.И. Вторенко, Ю.Г. Задорожный, Б.И. Леонов и др. // Электрохимическая активация в медицине, сельском хозяйстве, промышленности. III Международный симпозиум. М., 2001. С. 3-25.

13. Роль водного сегмента организма в процессах его жизнедеятельности: коллективная монография / Под ред. К.М. Резникова. Воронеж, 2014. 249 с.

14. Кузнецова Е.С. Возможности использования жидкостей с различным окислительно-восстановительным потенциалом при повреждениях кожи / Е.С. Кузнецова// В мире научных открытий. 2014. №11.10(59). С. 3816 3825.

15. Троценко Т.В. Восстановление кожи после химических пилингов / Т.В. Троценко // Kosmetik international. 2013. № 4. С. 90-101.

16. Адаскевич В.П. Диагностические индексы в дерматовенерологии. М.: Издательство Панфилова; БИНОМ, Лаборатория знаний, 2014. 352 с.

17. Хафизьянова P.X. Математическая статистика в экспериментальной и клинической фармакологии / Р.Х. Хафизьянова, И.М. Бурыкин, Г.Н. Алеева. Казань: Медицина, 2006. 374 с.

18. Hanaoka K. The mechanism of the enhanced antioxidant effects against superoxide anion radicals of reduced water produced by electrolysis / K. Hanaoka, D. Sun, R. Lawrence, Y. Kamitani, G. Fernandes // Biophys. Chem., 2004. V. 107(1). pp. 71-82. 
19. Lee M.Y. Electrolyzed-reduced water protects against oxidative damage to DNA, RNA, and protein / M.Y. Lee, Y.K. Kim, K.K. Ryoo, Y.B. Lee, E.J. Park // Appl. Biochem. Biotechnol., 2006. V. 135(2), pp. 133-144.

20. Clinical and instrumental evaluation of skin improvement after treatment with a new 50\% pyruvic acid peel. / E. Berardesca et al. // Dermatol Surg. 2006. Vol. 32(4), pp. 526-531.

\section{References}

1. Albanova V.I. Retinoidy - «zoloto» kosmetologii [Retinoides are the gold in cosmetology]. Esteticheskaya meditsina [Aesthetic medicine], 2009, issue 8 (4), pp. 385-394.

2. Kubanova, A.A. Khimicheskiy piling $\mathrm{v}$ kosmetologii [Chemical peeling in cosmetology]. Eksperimentalnaya $i$ klinicheskaya dermatokosmetologiya [Experimental and clinical dermatocosmetology], 2004, no. 1, pp. 24-28.

3. Kuznetsova E.S., Reznikov K.M. Optimizatsiya postpilingovykh protsessov v kosmetologii [Optimization of processes post-peeling in cosmetology]. Trudy XXI mezhdunarodnoy konferentsii i diskussionnogo nauchnogo kluba «Novye informatsionnye tekhnologii v meditsine, biologii, farmakologii $i$ ekologii» [Proc. of the XXI international conference and scientific discussion club «New Informational Technologies in Medicine, Biology, Pharmacology and Ecology»]. Ukraine, Crimea, Yalta-Gurzuf, 2013, pp. 133-134.

4. Skorogudaeva I.N. Khimicheskie pilingi segodnya: novye vozmozhnosti v borbe so stareniem [Chemical peels today: new opportunities in anti aging]. Kosmetik international, 2005. no 4, pp. 72-75.

5. Hernandes E.I. Lipidnyy bar'er kozhi i kosmeticheskie sredstva [Lipid barrier of the skin and cosmetic products]. Moscow, 2005. 252 p.

6. Hernandes E.I., Ponomarev I.V., Klyuchareva S.V. Sovremennye pilingi: khimicheskiy piling, lazernaya shlifovka, mekhanicheskaya dermabraziya, plazmennaya shlifovka [Modern peels: chemical peels, laser resurfacing, mechanical dermabrasion, and plasma resurfacing]. Moscow, 2011. 160 p.

7. Reznikov K.M., Brezdnyuk A.D., Latysheva Yu. N. Bezopasnost primeneniya elekroaktivirovannykh rastvorov natriya khlorida s lechebnoy tselyu: monografiya [The safety of electroactivated solutions of sodium chloride with the purpose of treatment: monograph]. Voronezh: VSMA, 2010. $144 \mathrm{p}$.

8. Ghersetich I., Brazzini B., Peris K., Cotellessa C., Manunta T., Lotti T. Pyruvic acid peels for the treatment of photoaging. Dermatologic Surgery, 2004, vol. 30 , no. 1 , pp. 32-36. 
9. Obagi Z.E. TCA-based blue peel: a standardized procedure with depth control. Dermatological Surgery, 1999. vol. 25, no 10, pp. 773-780.

10. Moy L.S., Howe K., Moy R.L. Glycolic acid modulation of collagen production in human skin fibroblast cultures in vitro. Dermatological Surgery, 1996, 22(5), pp. 439-441.

11. Devyatov V.A., Petrov S.V., Beloborodov V.A. Ispolzovanie neytralnogo anolita ANK pri preduprezhdenii gnoynykh oslozhneniy vospalitelnykh zabolevaniy [The use of neutral anolyte ANK in the prevention of septic complications of inflammatory diseases]. Dokladye i kratkie soobshchtnia Tretiyego mezhdunarodnogo simposiuma «Elektrokhimicheskaya aktivatsiya v meditsine, sel'skom khozyaystve, promyshlennosti» [Message and a short messages Third Intern. Symp. «Electrochemical activation in medicine, agriculture, industry»]. Moscow, 2001, pp. 133-135.

12. Bakhir V.M., Vtorenko V.I., Zadorozhnyy Yu.G., Leonov B.I. Nekotorye aspekty polucheniya i primeneniya elektrokhimicheski aktivirovannogo rastvora anolita ANK [Some aspects of production and application of electrochemically activated solution - anolyte ANK]. Elektrokhimicheskaya aktivatsiya $v$ meditsine, sel'skom khozyaystve, promyshlennosti. III Mezhdunarodnyy simpozium [Electrochemical activation in medicine, agriculture, industry. At the III international Symposium]. Moscow, 2001, pp. 3-25.

13. Reznikov K.M. Rol'vodnogo segmenta organizma v protsessakh ego zhiznedeyatel'nosti: kollektivnaya monografiya [The role of water segment of the body in the processes of his life: collective monograph under the editorship of K.M. Reznikov]. Voronezh, 2014. 249 p.

14. Kuznetsova E.S. Vozmozhnosti ispol'zovaniya zhidkostey s razlichnym okislitel'no-vosstanovitel'nym potentsialom pri povrezhdeniyakh kozhi [the Possibility of using fluids with different redox potential for skin lesions]. $V$ mire nauchnykh otkrytiy. [In the World of Scientific Discoveries]. 2014. no. 11.10(59), pp. 3816-3825.

15. Trotsenko T.V. Vosstanovlenie kozhi posle khimicheskikh pilingov [The Recovery of the skin after chemical peels]. Kosmetik international. 2013. no. 4, pp. $90-101$.

16. Adaskevich V.P. Diagnosticheskie indeksy v dermatovenerologii [Diagnostic indices in dermatology]. Moscow, Izdatel'stvo Panfilova Publ; BINOM, Laboratoriya znaniy, 2014. $352 \mathrm{p}$.

17. Khafizyanova R.Kh., Burykin I.M., Aleeva G.N. Matematicheskaya statistika $v$ eksperimental'noy i klinicheskoy farmakologii [Mathematical statistics in experimental and clinical pharmacology]. Kazan', Meditsina, 2006. 374 p. 
18. Hanaoka K., Sun D., Lawrence R., Kamitani Y., Fernandes G. The mechanism of the enhanced antioxidant effects against superoxide anion radicals of reduced water produced by electrolysis. Biophysical Chemistry, 2004. vol. 107(1), pp. 71-82.

19. Lee M.Y., Kim Y.K., Ryoo K.K., Lee Y.B., Park E.J. Electrolyzed-reduced water protects against oxidative damage to DNA, RNA, and protein. Applied Biochemistry and Biotechnology, 2006. vol. 135(2), pp. 133-144.

20. Berardesca E., Cameli N., Primavera G., Carrera M. Clinical and instrumental evaluation of skin improvement after treatment with a new 50\% pyruvic acid peel. Dermatological Surgery, 2006, vol. 32, no. 4, pp. 526-531.

\section{ДАННЫЕ ОБ АВТОРЕ}

Кузнецова Елена Сергеевна, аспирант кафедры фармакологии

Воронежский государственный медицинский университет им. Н.Н. Бурденко

ул. Студенческая, 10, г. Воронеж, 394036, Российская Федерация elenakusne@yandex.ru

\section{DATA ABOUT THE AUTHOR}

Kuznetsova Elena Sergeevna, Postgraduate Department of Pharmacology Voronezh State Medical University N.N. Burdenko 10, Studencheskaya Str., Voronezh, 394036, Russian Federation elenakusne@yandex.ru 